\title{
Involvement of proteasomal subunits zeta and iota in RNA degradation
}

\author{
Franck PETIT*, Anne-Sophie JARROUSSE*, Burkhardt DAHLMANN $\dagger$, Axel SOBEK†, Klavs B. HENDIL + , Jacques BURI§, \\ Yves BRIAND* and Hans-Peter SCHMID*1 \\ *Université Blaise Pascal, Clermont-Ferrand II, 24 Avenue des Landais, 63177 Aubière Cedex, France, †Diabetes Forschungsinstitut, Auf'm Hennekamp 65, \\ D-40225 Düsseldorf, Germany, \$August Krogh Institute, University of Copenhagen, 13 Universitetsparken, 2100 Copenhagen, Denmark, and §Station de Virologie et \\ d'Immunologie Moléculaire, INRA, Domaine de Vilvert, 78350 Jouy en Josas, France
}

\begin{abstract}
We have identified two distinct subunits of $20 \mathrm{~S}$ proteasomes that are associated with RNase activity. Proteasome subunits zeta and iota, eluted from two-dimensional Western blots, hydrolysed tobacco mosaic virus RNA, whereas none of the other subunits degraded this substrate under the same conditions. Additionally, proteasomes were dissociated by $6 \mathrm{M}$ urea, and subunit zeta, containing the highest RNase activity, was isolated by anionexchange chromatography and gel filtration. Purified subunit
\end{abstract}

zeta migrated as a single spot on two-dimensional PAGE with a molecular mass of approx. $28 \mathrm{kDa}$. Addition of anti-(subunit zeta) antibodies led to the co-precipitation of this proteasome subunit and nuclease activity. This is the first evidence that proteasomal $\alpha$-type subunits are associated with an enzymic activity, and our results provide further evidence that proteasomes may be involved in cellular RNA metabolism.

\section{INTRODUCTION}

The sub-ribosomal fractions of eukaryotic cells contain a number of protein complexes with a relatively high sedimentation rate. Most abundant are the $20 \mathrm{~S}$ proteasomes, which associate with other particles to form larger complexes. One of these, the $26 \mathrm{~S}$ proteasome, has attracted much attention during the last few years [1-3], as it has the ability to degrade protein-ubiquitin conjugates in an ATP-dependent reaction [4,5]. Furthermore, proteasomes are involved in cell cycle control [6,7], in early steps of the immune response [8,9] and in transcriptional regulation $[10,11]$, and recently published data suggest that proteasomes may also participate in the pathways of cellular RNA breakdown $[12,13]$.

Proteasomes have a cylindrical structure. The cylinder consists of a stack of four discs or rings, each of which is composed of seven subunits with molecular masses of between 19 and $35 \mathrm{kDa}$. Two-dimensional protein gel electrophoresis has revealed up to 20 individual proteins, with the number varying between cells and species [14-20]. In addition, proteasomes were reported to contain about $0.0016-0.2 \%$ low-molecular-mass RNAs. The RNA content depends on the origin of the proteasomes, and decreases with increasing proteasome purity $[13,21]$. These RNAs are heterogeneous in size, but migrate most frequently in a molecular size range of 70-120 nucleotides [22-24]. Partial sequence analysis of proteasomal RNA has revealed that no particular species of RNA is specifically associated with the proteasomes [21]. Thus proteasomal RNAs were suggested to represent contamination of purified proteasomes [21] or residual substrate fragments of a specific proteasomal RNase activity $[12,25]$. The latter hypothesis is attractive, since it has been shown that nuclease activity is an integral part of proteasomes. Using different types of chromatography, Pouch et al. [12] have shown that RNase activity was coincident with the elution profiles at each state of purification, and that nuclease activity was resistant to strong dissociation conditions using $0.5 \%$ lauroylsarkosyl-Na and $6 \mathrm{M}$ urea.

In the present paper, we demonstrate that two proteasome $\alpha$ type subunits are responsible for RNA hydrolysis. Subunit zeta showed the most rapid cleavage reaction, whereas subunit iota was less active. No other proteasome subunits tested degraded tobacco mosaic virus (TMV) RNA under the same conditions.

\section{EXPERIMENTAL}

\section{Definition of TBK buffers}

Buffer TBK $X$ consists of $20 \mathrm{mM}$ Tris/HCl, pH 7.0, $X \mathrm{mM} \mathrm{KCl}$, $2.5 \mathrm{mM} \mathrm{MgCl}_{2}$ and $7 \mathrm{mM} 2$-mercaptoethanol, where $X$ is 0,50 , $120,240,300$ or 480 .

\section{Cell fractionation and isolation of proteasomes from calf liver cells}

The preparation of the post-mitochondrial supernatant has been described [26]. Proteasomes were isolated from the post-mitochondrial supernatant by several ultracentrifugation steps. The final purification was by FPLC (Pharmacia) using Mono Q and Superose 6 columns, as reported previously [12].

\section{Assay of RNA digestion}

Purified TMV RNA from Nicotiana rustica was purchased from DSM (Braunschweig, Germany). A portion of $4 \mu \mathrm{g}$ of TMV RNA was incubated for $20 \mathrm{~min}$ with or without proteasomes or proteasome proteins at $37^{\circ} \mathrm{C}$. The volume of each assay was $200 \mu 1$, and the incubation buffer was TBK 120. After incubation, the assays were applied to a Superose 6 column equilibrated in TBK 120 containing $3 \mathrm{mM}$ EDTA. The percentage degradation of RNA was calculated by measuring the peaks of absorbance at $280 \mathrm{~nm}$ before and after digestion.

\section{Protein gel electrophoresis}

Proteins were precipitated with $10 \%(\mathrm{w} / \mathrm{v})$ trichloroacetic acid (final concentration). Electrophoresis of proteins was performed 
on one-dimensional SDS/polyacrylamide gels [27]. Two-dimensional gel electrophoresis was performed according to [28] using Ampholines (Pharmacia) in the $\mathrm{pH}$ range 3.5-10. For the first dimension, the gels were run at $400 \mathrm{~V}$ for $12 \mathrm{~h}$, and then, for the second dimension, at $800 \mathrm{~V}$ for $1 \mathrm{~h}$. Molecular mass markers were phosphorylase $b(94 \mathrm{kDa})$, BSA $(68 \mathrm{kDa})$, ovalbumin $(43 \mathrm{kDa})$, carbonic anhydrase $(29 \mathrm{kDa})$, soy bean trypsin inhibitor $(20 \mathrm{kDa})$ and lactalbumin $(14 \mathrm{kDa})$.

\section{Immunoblotting}

After electrophoresis, the proteins were transferred to a nitrocellulose membrane using a Trans-Blot SD Semi-Dry Transfer Unit (Bio-Rad) in a buffer containing $25 \mathrm{mM}$ Tris $/ \mathrm{HCl}, \mathrm{pH} 8.3$, $192 \mathrm{mM}$ glycine and $20 \%(\mathrm{v} / \mathrm{v})$ methanol. After $1 \mathrm{~h}$ of transfer, the membrane was blocked for at least $1 \mathrm{~h}$ in $5 \%(\mathrm{w} / \mathrm{v})$ non-fat dried milk in TTBS buffer [20 mM Tris/ $\mathrm{HCl}, \mathrm{pH} 7.4,500 \mathrm{mM}$ $\mathrm{NaCl}$ and $0.1 \%(\mathrm{v} / \mathrm{v})$ Tween 20]. The membrane was then washed for $3 \times 15 \mathrm{~min}$ at $37^{\circ} \mathrm{C}$ in TTBS before incubation with one of the monoclonal antibodies (IB5, purchased from Cappel; or MCP196) diluted 1:2000 in TTBS overnight at room temperature. After washing in TTBS, the membrane was incubated with alkaline phosphatase-labelled anti-mouse IgG antibodies diluted $1: 2000$ in TTBS for $1 \mathrm{~h}$ at $37^{\circ} \mathrm{C}$. The membrane was then washed again, and alkaline phosphatase-conjugated antibodies were detected by the Nitro Blue Tetrazolium/5-bromo-4-chloro3-indolyl phosphate substrate system [29].

\section{Immunoprecipitation}

The mouse IgG anti-(subunit zeta) antibody MCP196 was purified from mouse peritoneal fluid using an FPLC Protein A-Superose column (Pharmacia) [29]. Purified $28 \mathrm{kDa}$ protein was incubated with anti-(subunit zeta) antibody [30] for $2 \mathrm{~h}$ at room temperature. Then Protein A-Sepharose CL-4B (Pharmacia) was added (5\% final concentration) and the incubation continued for $1 \mathrm{~h}$ with gentle agitation at room temperature. After $5 \mathrm{~min}$ of centrifugation (10000 $\mathrm{g}$; Hettich Mikroliter), the supernatant was subjected to SDS/PAGE or assayed for RNase activity.

\section{Recovery of proteasome subunits from electroblots}

Proteasomal proteins were separated by two-dimensional PAGE and transferred to nitrocellulose sheets by semi-dry blotting. The different subunits were visualized by Ponceau Red. Then the stained spots were cut out, and proteins were eluted from the membrane in $200 \mu \mathrm{l}$ of TBK 240 containing $10 \%(\mathrm{v} / \mathrm{v})$ acetonitrile and $0.2 \%(\mathrm{w} / \mathrm{v})$ Triton $\mathrm{X}-100$ for $5 \mathrm{~h}$ at $37^{\circ} \mathrm{C}$ [31].

\section{RESULTS}

\section{Localization of RNase activity on proteasome subunits}

Previously published data indicated that the integrity of the proteasome complex is not necessary for RNase activity [12]. Thus we assumed that dissociation of proteasomes could represent a useful method for the isolation of proteasomal subunits that hydrolyse RNA.

In a preliminary series of investigations, purified proteasomes were dissociated by $8 \mathrm{M}$ urea and subunits were separated by two-dimensional PAGE (Figure 1). After transfer to nitrocellulose sheets, individual proteasomal subunits were eluted with buffers containing acetonitrile and Triton X-100 [31] and then tested for RNase activity. Staining of nitrocellulose sheets with Ponceau Red before and after elution revealed that approx. $80 \%$
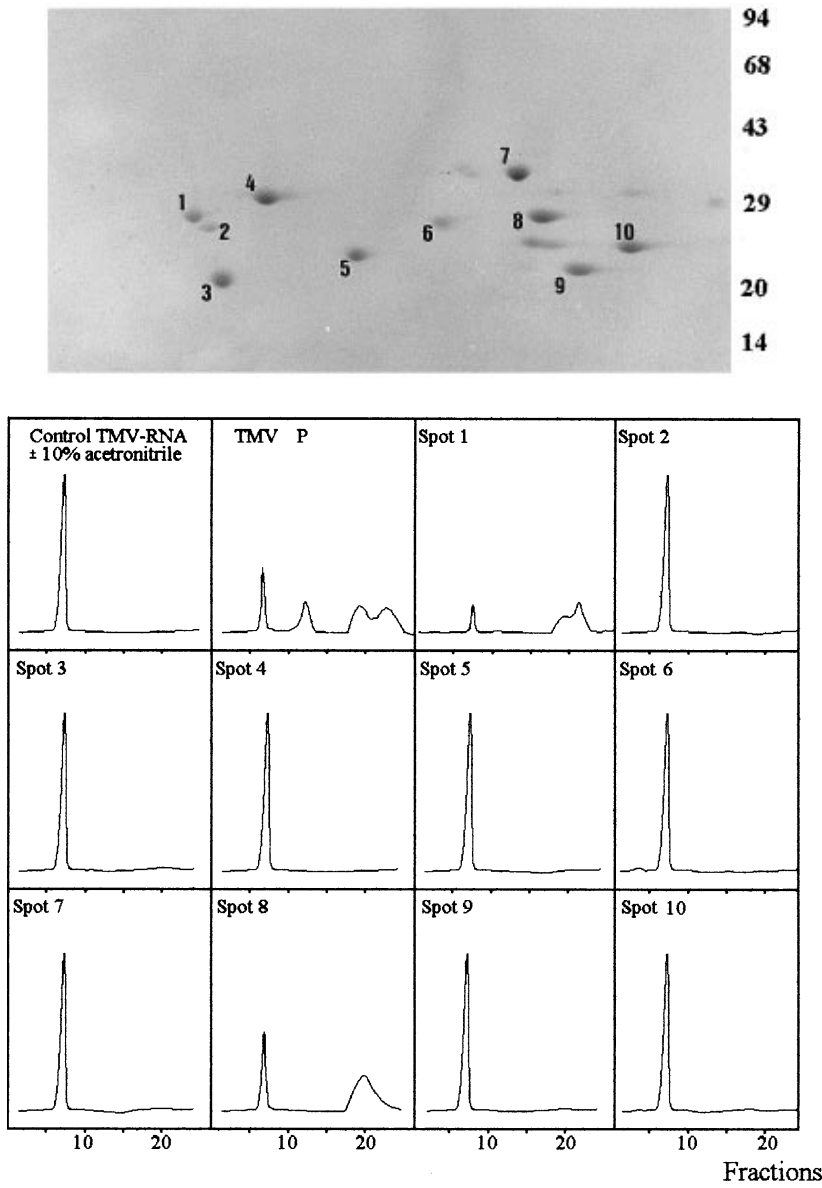

Figure 1 Screening of proteasome subunits for RNase activity

Proteasomes subunits were separated by two-dimensional PAGE and transferred to nitrocellulose sheets. Ponceau Red-stained protein spots (upper panel) were cut out and eluted from the membrane with TBK 240 containing 10\% acetonitrile and 0.2\% Triton X-100 (see the Experimental section). The eluted fractions (200 $\mu \mathrm{l}$ ) were incubated with $4 \mu \mathrm{g}$ of TMV RNA for 20 min at $37^{\circ} \mathrm{C}$, and then the total assay was analysed by gel filtration on Superose 6 columns (lower panels). The percentage degradation of RNA was calculated as described in the Experimental section: spot 1/subunit zeta, $70-80 \%$; spot 8/subunit iota, 30-40\%; other numbered spots, $0-2 \%$. P indicates total proteasome. Absorbance at $280 \mathrm{~nm}$ is shown. Proteasomal subunits iota and zeta were identified by immunoblotting using the monoclonal antibodies MCP196 (zeta) and IB5 (iota). The numbers to the right of the upper panel indicate molecular mass $(\mathrm{kDa})$

of transferred proteins were recovered (results not shown). To demonstrate RNase activity we used as a substrate TMV RNA, a polycistronic messenger with an apparent molecular mass of about $2000 \mathrm{kDa}$, which separates well from $20 \mathrm{~S}$ proteasomes $(700 \mathrm{kDa})$ on gel-filtration columns ([12]; see the Experimental section). These experiments revealed that the major activity was associated with subunit zeta, while lower activity was detected when subunit iota was present (Figure 1). None of the other proteasomal subunits eluted from the nitrocellulose sheets cleaved TMV RNA under the same conditions (Figure 1).

\section{Purification of subunit zeta associated with RNase activity}

To confirm our findings, we decided to purify subunit zeta, as it had the highest RNA cleavage activity. In this approach, proteasomes were dissociated in urea and the subunits were separated by ion-exchange chromatography on Mono Q. Proteasomal subunits were eluted in the range $100-300 \mathrm{mM} \mathrm{KCl}$ with 

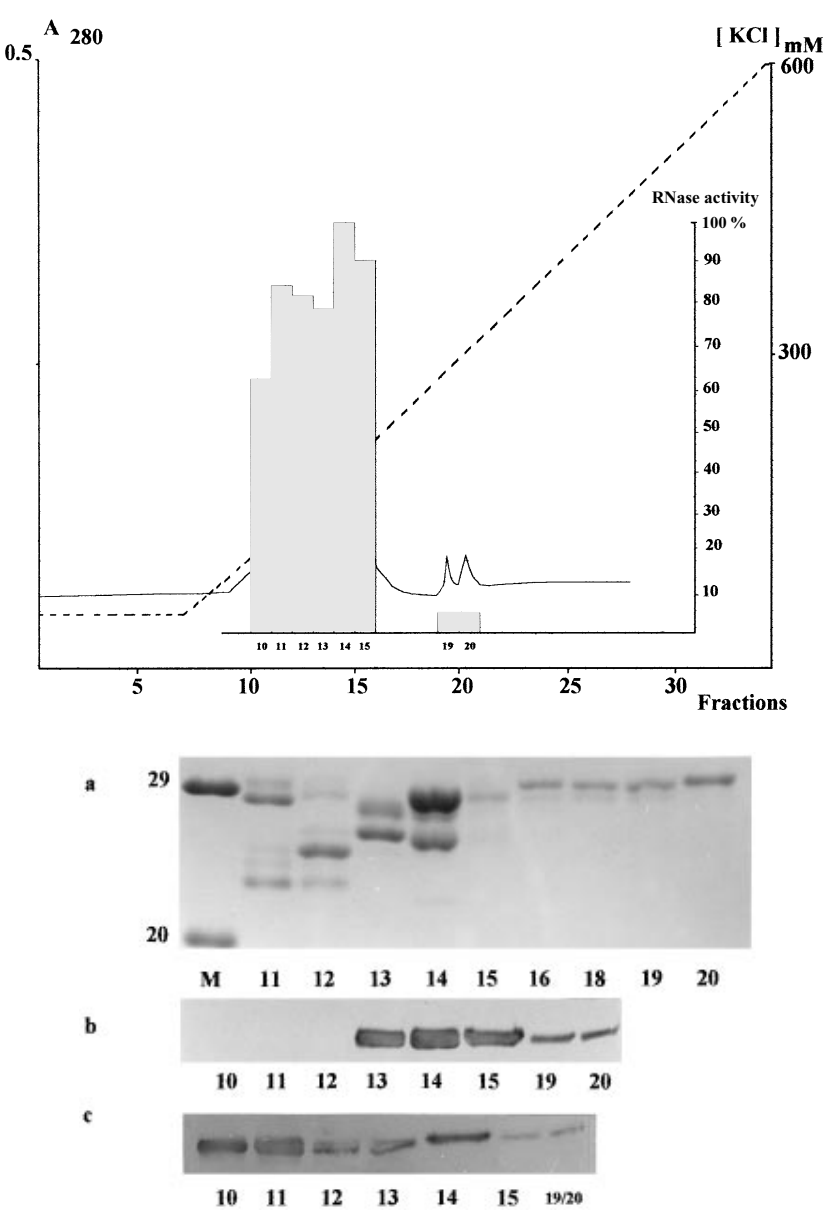

Figure 2 Co-elution of RNase activity with proteasomal subunits

Top panel: $2 \mathrm{mg}$ of highly purified proteasomes eluted from Superose 6 columns was dialysed against TBK 0 , and then incubated for $10 \mathrm{~min}$ at $37^{\circ} \mathrm{C}$ with $6 \mathrm{M}$ urea (final concentration). The suspension was loaded on to an FPLC Mono Q HR $5 / 5$ column equilibrated in TBK 0 containing $6 \mathrm{M}$ urea. Proteasomal subunits were eluted with a linear salt gradient containing $6 \mathrm{M}$ urea from TBK 0 to TBK 600. Eluted fractions were dialysed against TBK 120, and $200 \mu \mathrm{l}$ aliquots were incubated with $4 \mu \mathrm{g}$ of TMV RNA for 20 min at $37^{\circ} \mathrm{C}$ to analyse RNase activity, as described in the Experimental section. RNase activity is shown by the bar diagram, the solid line indicates $A_{280}$, and the broken line indicates $\mathrm{KCl}$ concentration. (a-c) Distribution of subunits zeta and iota in fractions eluted from FPLC Mono $Q$ columns. Portions of $800 \mu$ l of fractions 11-20 (top panel) were incubated with $10 \%$ trichloroacetic acid (final concentration) to precipitate the proteins. Sedimented proteins were analysed by PAGE. After gel electrophoresis, proteins were transferred to nitrocellulose filters and probed with the monoclonal antibodies MCP196 and IB5. Mouse lgG was detected as described in the Experimental section. (a) Proteasome subunits visualized by Coomassie Blue staining (lane $\mathrm{M}$ contains molecular mass markers; $\mathrm{kDa}$ ); (b) subunit zeta detected by MCP196; (c) subunit iota detected by IB5.

a heterogeneous profile of absorbance (Figure 2, top panel). PAGE of the eluted fractions revealed that most fractions contained more than one proteasomal subunit (Figure 2a). Two proteasomal proteins larger than $29 \mathrm{kDa}$ were eluted separately in the range $150-300 \mathrm{mM} \mathrm{KCl}$ from the bulk of proteasomal subunits and contained only very low RNase activity (Figure 2, top panel, fractions 19 and 20; and Figure 2a, lanes 18-20).

The major part of the RNase activity co-eluted with the bulk of proteasome subunits, and analysis by immunoblotting with antibodies MCP 196 and IB5 (Figures 2b and 2c) demonstrated that all fractions eluted from the Mono Q column contained at least one of the two subunits exhibiting RNase activity, i.e. zeta and iota. Only in fractions $10-12$ was subunit zeta completely
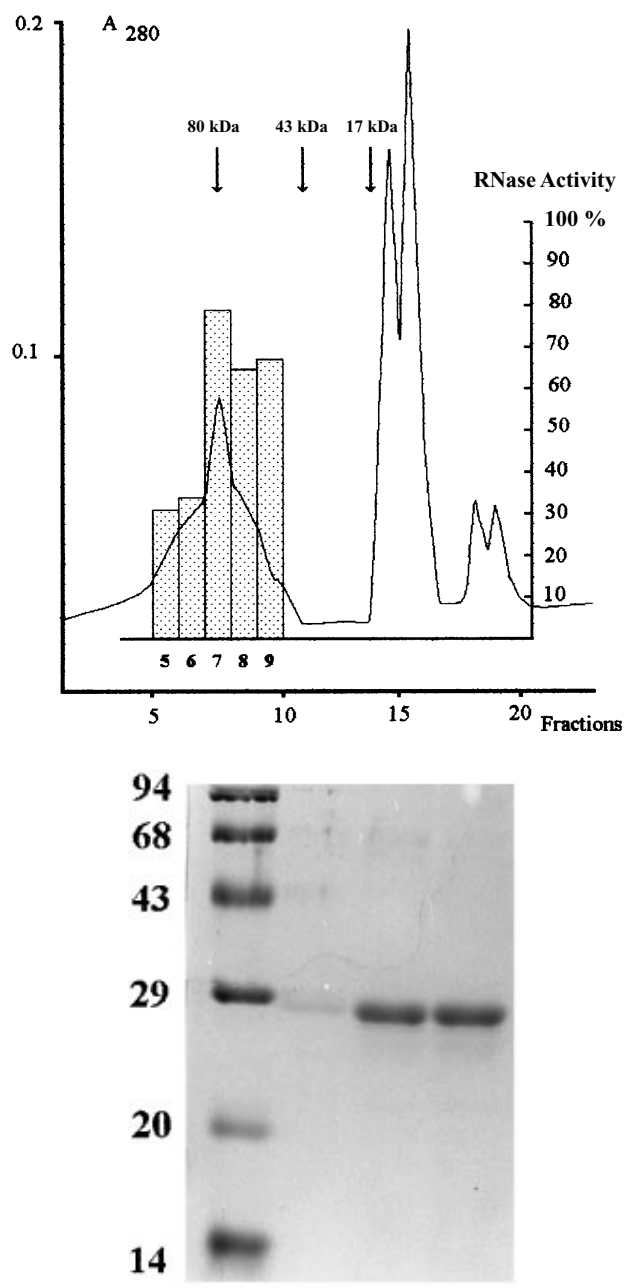

$\begin{array}{llll}\mathbf{M} & \mathbf{a} & \mathbf{b} & \mathbf{C}\end{array}$

Figure 3 Analysis by gel filtration of fraction 14 eluted from the FPLC Mono $Q$ column

Upper panel: fraction 14 obtained by Mono $Q$ chromatography (Figure 2) was applied on an FPLC Superdex 75 column equilibrated in TBK 120 containing $6 \mathrm{M}$ urea. Eluted fractions were dialysed against TBK 120 to eliminate urea. Samples (200 $\mu \mathrm{l}$ of the $1 \mathrm{ml}$ fractions 5-9) were incubated with $4 \mu \mathrm{g}$ of TMV RNA for 20 min at $37^{\circ} \mathrm{C}$ to assay RNase activity. RNase activity is shown by the bar diagram; the line indicates $A_{280}$. Lower panel: for PAGE, eluted fractions were pooled (lane a, 5+6; lane b, 7; lane c, 8+9) and dialysed against TBK 120 to eliminate urea. Samples $(800 \mu \mathrm{l})$ of the pooled fractions were incubated with $10 \%(\mathrm{w} / \mathrm{v})$ trichloroacetic acid (final concentration) to precipitate the proteins. Sedimented proteins were analysed by SDS/PAGE and the gels were stained with Coomassie Blue. Lane M contains molecular mass markers $(\mathrm{kDa})$.

absent. Thus treatment of proteasomes with $6 \mathrm{M}$ urea and subsequent chromatography on Mono Q only partially dissociates the $20 \mathrm{~S}$ complex.

For further purification of the RNase-containing proteasome subunit, fraction 14 from Mono Q chromatography, which had the highest RNase activity (Figure 2, top panel) and the highest subunit zeta content (Figure 2a), was analysed further by gel filtration on a Superdex 75 column (Figure 3, upper panel). To our surprise, all protein co-eluted with RNase activity in fractions 5-9, corresponding to a molecular mass range of 40-90 kDa, and PAGE revealed that these fractions contained exclusively 


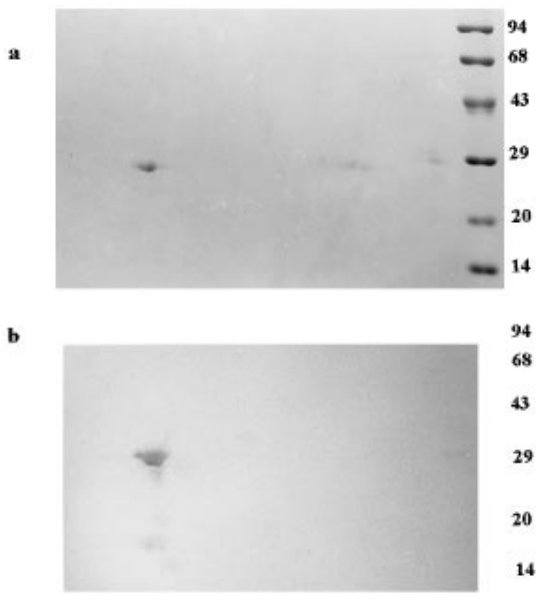

Figure 4 Two-dimensional PAGE analysis of purified subunit zeta

Subunit zeta of proteasomes purified by gel filtration on FPLC Superdex 75 (see Figure 3) was analysed by two-dimensional PAGE, and then the proteins were transferred to a nitrocellulose sheet and probed with antibody MCP 196, as indicated in the Experimental section. (a) Coomassie Blue staining of purified subunit zeta; (b) immunoblot of purified subunit zeta detected with antibody MCP 196. Positions of molecular mass markers ( $\mathrm{KDa}$ ) are indicated on the right.

proteasome subunits with a molecular mass of $28 \mathrm{kDa}$ (Figure 3, lower panel). We concluded that these subunits are $\alpha$-type subunits that were eluted as oligomeric aggregates under the conditions employed. Indeed, such self-aggregation was also described for $\alpha$-type subunits expressed in bacteria, whereas proteasomal $\beta$-type subunits, which are all smaller than $27 \mathrm{kDa}$, do not polymerize [32a]. This would explain the good separation by gel filtration of $\alpha$-type from $\beta$-type subunits with quite similar molecular masses (Figure 2b, lane 14; Figure 3, lower panel).

For further analysis, fractions 5-9 containing the $28 \mathrm{kDa}$ protein (see Figure 3) were subjected to two-dimensional PAGE. Figure 4(a) demonstrates that the $28 \mathrm{kDa}$ protein migrated as a single spot. Comparison of the protein pattern of intact $20 \mathrm{~S}$ proteasomes (Figure 1) with the migration of the $28 \mathrm{kDa}$ protein on two-dimensional gels (Figure $4 \mathrm{a}$ ) shows that the $28 \mathrm{kDa}$ subunit is the most acidic protein, corresponding to subunit zeta of the $20 \mathrm{~S}$ proteasome complex [30]. Figure 4(b) demonstrates that the $28 \mathrm{kDa}$ protein is actually recognized by monoclonal antibody MCP196, which is specific for subunit zeta. In addition, incubation of a suspension of purified $28 \mathrm{kDa}$ protein with MCP 196 led to complete precipitation of this proteasomal subunit (Figure 5b, inset, lane 2), and the remaining supernatant was free of RNase activity (Figure 5b). From these experiments, we conclude that the RNase activity of $20 \mathrm{~S}$ proteasomes is associated with subunit zeta.

Additionally, we tested the largest proteasome subunit, $\mathrm{C} 2$, for RNase activity. This proteasomal subunit is known to dissociate easily from the $20 \mathrm{~S}$ proteasome complex; it is absent from urearesistent proteasome subcomplexes that still harbour RNase activity [12]. For purification, material in fraction 20 of several runs on FPLC Mono Q columns was pooled (Figure 2a) and subjected to gel filtration on an FPLC Superdex 75 column under the same conditions as described for the purification of subunit zeta (Figure 3). Analysis of the eluted fractions by PAGE showed that this proteasomal subunit migrated as single band of approx. $32 \mathrm{kDa}$ (Figure 5c, inset). This subunit did not hydrolyse TMV RNA under the conditions employed (Figure 5c).

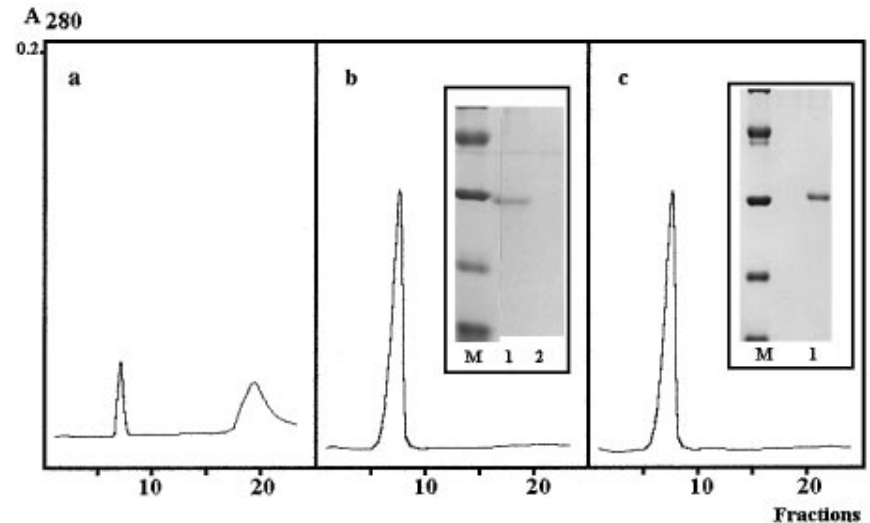

Figure 5 RNase activity of proteasome subunit zeta and subunit of $32 \mathrm{kDa}$

Proteasome subunit zeta eluted from FPLC Superdex 75 columns (see Figure 3), as well as C2 purified from fraction 20 of Figure 2, were dialysed against TBK 120 to eliminate urea and incubated with TMV RNA for $20 \mathrm{~min}$ at $37^{\circ} \mathrm{C}$. Subsequently the total assay $(200 \mu \mathrm{l})$ was immediately analysed by chromatography on FPLC Superose 6 equilibrated in TBK 120. (a) TMV RNA $(4 \mu \mathrm{g})$ was incubated with $200 \mu \mathrm{l}$ samples of fractions containing purified proteasome subunit zeta. (b) A suspension of subunit zeta in TBK 120 was incubated for $2 \mathrm{~h}$ with monoclonal antibody MCP196 in the presence of Protein A-Sepharose. Immunocomplexes bound to Protein A-Sepharose were sedimented by centrifugation and $200 \mu \mathrm{l}$ of the supernatant was assayed for RNase activity for $20 \mathrm{~min}$ at $37^{\circ} \mathrm{C}(4 \mu \mathrm{g}$ of TMV RNA) or subjected to PAGE [inset: lane 1, subunit zeta (control); lane 2, supernatant after immunoprecipitation; lane M, molecular mass markers]. (c) Fraction 20 eluted from FPLC Mono $Q$ columns (Figure 2) and containing the largest proteasome subunit C2 were subjected to gel filtration on Superdex 75 columns under the same conditions as described in the legend to Figure 3. Eluted fractions showing the highest absorbance at $280 \mathrm{~nm}$ were dialysed against TBK 120 to eliminate urea. Then they were incubated with $10 \%(\mathrm{w} / \mathrm{v})$ trichloroacetic acid (final concentration) to precipitate the proteins. Sedimented proteins were analysed by SDS/PAGE (inset). Alternatively, $200 \mu \mathrm{l}$ portions of the dialysed fractions were tested for RNase activity by gel filtration as described above.

\section{DISCUSSION}

Previous reports have shown that proteasomes are completely dissociated by treatment with SDS or bivalent ions such as $\mathrm{Zn}^{2+}$ [33]. Incubation with mercurial chloromercuribenzoic acid led to the formation of a heterogeneous population of proteasomal subcomplexes and subunits, as analysed by PAGE [34]. In addition, reverse-phase chromatography was shown to be a powerful tool for the isolation of distinct proteasomal subunits [35]. However, under these conditions the proteolytic activities of proteasomes were abolished.

Here we show that incubation of proteasomes with $6 \mathrm{M}$ urea is a valuable method for the dissociation of proteasomes into subcomplexes and subunits that retain RNase activity. It should be noted that, under these conditions, not only the RNase activity, but also the proteasomal chymotrypsin-like activity, is preserved (J. Buri, F. Petit, Y. Briand and H. P. Schmid, unpublished work). For the isolation of individual proteasome subunits, it was necessary to carry out all chromatographic procedures in the presence of $6 \mathrm{M}$ urea to avoid partial or total reconstitution of proteasomes. Nevertheless the purified $28 \mathrm{kDa}$ subunit of proteasomes showed a high tendency to polymerize, even in the presence of high concentrations of urea, since it was eluted from gel-filtration columns in fractions corresponding to molecular masses of up to $90 \mathrm{kDa}$. We took advantage of this aggregation of $\alpha$-type subunits to separate them by gel filtration from non-polymerizing $\beta$-subunits. Interestingly, the purified 
$28 \mathrm{kDa}$ protein had an approx. 10-fold higher nuclease activity than the same amount ( $A_{280}$ units) of intact proteasomes. This confirms our findings, shown in Figure 1, that just two of the various proteasome subunits eluted from nitrocellulose sheets contained this activity. All proteolytic activities of proteasomes investigated so far have been associated with the $\beta$-type subunits, and the role of the $\alpha$-type subunits has remained speculative (reviewed in [36]). $\alpha$-Type subunits act as linkers between the $19 \mathrm{~S}$ regulator complex and the $20 \mathrm{~S}$ proteasome to build up the $26 \mathrm{~S}$ proteasome [37]. However, as clearly demonstrated here, some $\alpha$-type subunits, such as subunit zeta, are also associated with the expression of an enzymic activity, namely RNase. Subunit iota, another $\alpha$-type subunit of proteasomes, also degrades TMV RNA, but is less active than subunit zeta. Accordingly, it is possible that the two individual subunits form separate nucleolytic centres. In this respect subunit iota, which was reported to contain an RNA binding domain [38], could be implicated in the recognition of RNA substrates. Work is in progress to purify subunit iota to homogeneity for further investigations.

Our work supports recent findings [12] that RNase activity is an integral part of proteasomes, indicating the existence of a close relationship between proteasomes and RNA. In this context, $20 \mathrm{~S}$ proteasomes (prosomes) were detected as factors that control translation in Friend virus-infected mouse erythroblasts by transient association with untranslatable free mRNA [19]. Indeed, several experimental findings support the idea that proteasomes could act as rather selective repressors of translation, as they inhibit in vitro protein synthesis of mRNA from adenovirus-infected HeLa cells and the translation of polycistronic TMV RNA, whereas the translation of HeLa mRNA and globin mRNA is not affected under the same conditions [39]. Previous work has shown that proteasomes interfere with the initiation of protein synthesis and prevent the formation of $80 \mathrm{~S}$ initiation complexes. TMV RNA cannot associate with the $40 \mathrm{~S}$ ribosomal subunits, due to the RNase activity of proteasomes $[12,40]$.

How proteasomes select mRNAs for degradation remains unknown. We assume that sequences or secondary structures exist that are recognized by $20 \mathrm{~S}$ proteasomes. Work on mRNA decay has shown that sequence elements such as the $3^{\prime}$ untranslated region regulate the degradation of different eukaryotic messengers. The best studied examples are the iron-response element stem-loop structures on transferrin mRNA and the ARE (see below), which are present in many unstable mRNAs. While the association of a $90 \mathrm{kDa}$ protein with the iron-response element stabilizes transferrin mRNA, its dissociation favours the binding of destabilizing factors. These factors could be ribonucleases or proteins that may recruit ribonucleases to destroy transferrin mRNA [41,42]. The second well characterized mRNA-destabilizing sequence is an AUUUA-rich region within the $3^{\prime}$ untranslated region, named the ARE [43]. Characteristic classes of ARE-containing mRNAs include cytokine, lymphokine and oncogene mRNAs [41]. Among the proteins that associate specifically with the ARE, a $20 \mathrm{~S}$ protein complex with unknown protein composition was described and found to be involved in the modulation of the stabilization of ARE elements [44]. Interestingly, $20 \mathrm{~S}$ proteasomes and this $20 \mathrm{~S}$ protein complex share common properties, e.g. similar size, association with mRNAs and destabilization of RNAs. In addition, preliminary experiments in our laboratory indicate that proteasome-associated RNase activity cleaves AUUUA-rich oligo-RNAs specifically (A.-S. Jarrousse, unpublished work). Future work will show whether proteasomes and this $20 \mathrm{~S}$ protein complex are analogues or homologous structures.
This work was supported by the European Community Biomed II Programme, the Hasselblad Foundation, the Ministère de la Recherche et Technologie, the Conseil Régional Auvergne, the Agence National de Recherche sur le Sida, and the Fondation pour la Recherche Médicale (Sidaction), France.

\section{REFERENCES}

1 Hough, R., Pratt, G. and Rechsteiner, M. (1987) J. Biol. Chem. 262, 8303-8313

2 Coux, O., Tanaka, K. and Goldberg, A. L. (1996) Annu. Rev. Biochem. 65, 801-847

3 Peters, J. M., Cejka, Z., Harris, J. R., Kleinschmidt, J. A. and Baumeister, W. (1993) J. Mol. Biol. 234, 932-937

4 Eytan, E., Gannoth, D., Armon, T. and Hershko, A. (1989) Proc. Natl. Acad. Sci. U.S.A. 86, 7751-7755

5 Ciechanover, A. (1994) Cell 79, 13-21

6 Gordon, C., McGurk, G., Dillon, P., Rosen, C. and Hastie, N. D. (1993) Nature (London) 366, 355-357

7 Ghislain, M., Udvardy, A. and Mann, C. (1993) Nature (London) 366, 358-361

8 Goldberg, A. L. and Rock, K. L. (1992) Nature (London) 357, 375-378

9 Belich, M. P. and Trowsdale, J. (1995) Mol. Biol. Rep. 21, 53-56

10 Richter-Ruoff, B., Wolf, D. H. and Hochstrasser, M. (1994) FEBS Lett. 354, 50-52

11 Orian, A., Whiteside, S., Israel, A., Stancovski, I., Schwartz, A. L. and Ciechanover, A. (1995) J. Biol. Chem. 270, 21707-21714

12 Pouch, M. N., Petit, F., Buri, J., Briand, Y. and Schmid, H. P. (1995) J. Biol. Chem. 270, 22023-22028

13 Schmid, H. P., Pouch, M. N., Petit, F., Dadet, M. H., Badaoui, S., Boissonnet, G., Buri, J., Norris, V. and Briand, Y. (1995) Mol. Biol. Rep. 21, 43-47

14 Pühler, G., Weinkauf, S., Bachmann, L., Müller, S., Engel, A., Hegerl, R. and Baumeister, W. (1992) EMBO J. 11, 1607-1616

15 Kleinschmidt, J. A., Hügle, C., Grund, W. and Franke, W. W. (1983) Eur. J. Cell Biol. 32, 143-156

16 Martins de Sa, C., Grossi de Sa, M. F., Akhayat, O., Broders, F., Scherrer, K., Horsch, A. and Schmid, H. P. (1986) J. Mol. Biol. 187, 479-493

17 Schliephacke, M., Kremp, A., Schmid, H. P., Köhler, K. and Kull, U. (1991) Eur. J. Cell Biol. 55, 114-121

18 Grziwa, A., Baumeister, W., Dahlmann, B. and Kopp, F. (1991) FEBS Lett. 290 186-190

19 Schmid, H. P., Akhayat, O., Martins de Sa, C., Puvion, F., Köhler, K. and Scherrer, K. (1984) EMBO J. 3, 29-34

20 Falkenburg, P. E., Haas, C., Kloetzel, P. M., Niedel, B., Kopp, F., Kuehn, L. and Dahlmann, B. (1988) Nature (London) 331, 190-192

21 Pamnani, V., Haas, B., Pühler, G., Sänger, H. L. and Baumeister, W. (1994) Eur. J. Biochem. 225, 511-519

22 Dineva, B., Tomek, W., Köhler, K. and Schmid, H. P. (1989) Mol. Biol. Rep. 13, 207-211

23 Arrigo, A. P., Darlix, J. L., Khandjian, E. W., Simon, M. and Spahr, P. F. (1985) EMBO J. 4, 399-406

24 Horsch, A., Köhler, K., Ellwart-Tschürz, M. and Schmid, H. P. (1990) FEBS Lett. 269 336-340

25 Tsukahara, T., Tanaka, K., Ogawa, T., Ishiura, S., Funabiki, R. and Sugita, H. (1989) FEBS Lett. 255, 179-183

26 Tomek, W., Buri, J., Vallon, R. and Schmid, H. P. (1990) J. Chromatogr. 521, 221-229

27 Laemmli, U.K. (1970) Nature (London) 227, 680-685

28 O'Farrell, P. Z., Goodmann, H. and O'Farrell, P. H. (1977) Cell 12, 1133-1142

29 Blake, M. S., Johnston, K. H., Russell-Jones, G. J. and Gotschlich, E. C. (1984) Anal. Biochem. 136, 175-179

30 Kristensen, P., Johnsen, A. H., Uerkvitz, W., Tanaka, K. and Hendil, K. B. (1994) Biochem. Biophys. Res. Commun. 205, 1785-1789

31 Parekh, B. S., Mehta, B., West, M. D. and Montelaro, R. C. (1985) Anal. Biochem. 148, 87-92

32 Zwickl, P., Kleinz, J. and Baumeister, W. (1994) Struct. Biol. 1, 765-770

$32 a$ Gerards, W. L. H., Eutlin, J., Häner, M., Hendriks, A. M., Aebi, U., Bloemendal, H. and Boelens, W. (1997) J. Biol. Chem. 272, 10080-10086

33 Nothwang, H. G., Coux, O., Bey, F. and Scherrer, K. (1992) Biochem. J. 287 733-739

34 Figueiredo-Pereira, M. E., Yu, B. and Wilk, S. (1994) J. Biol. Chem. 269, 621-626

35 Tanaka, K., Yoshimura, T., Ichihara, A., Ikai, A., Nishigai, M., Monimoto, Y., Sato, M., Tanaka, N., Katsube, Y., Kameyama, U. and Takagi, T. (1988) J. Mol. Biol. 203, 985-996

36 Hilt, W. and Wolf, D. H. (1995) Mol. Biol. Rep. 21, 3-10

37 Realini, C., Rogers, S. W. and Rechsteiner, M. (1994) FEBS Lett. 348, 109-113

38 Bey, F., Pereira, S., Coux, O., Viegas-Pequignot, E., Recillas-Targa, F., Nothwang, H. G., Dutrillaux, B. and Scherrer, K. (1993) Mol. Gen. Genet. 237, 193-209 
39 Horsch, A., Martins de Sa, Dineva, B., Spindler, E. and Schmid, H. P. (1987) FEBS Lett. 246, 131-136

40 Homma, S., Horsch, A., Pouch, M. N., Petit, F., Briand, Y. and Schmid, H. P. (1994) Mol. Biol. Rep. 20, 57-61

41 Klausner, R. D., Ronault, T. A. and Harford, J. B. (1993) Cell 72, 19-28

42 Sachs, A. B. (1993) Cell 74, 413-421

43 Shaw, G. and Kamen, R. (1986) Cell 46, 659-667

44 Savant-Bhonsale, S. and Cleveland, D. W. (1992) Genes Dev. 6, 1927-1939

Received 30 September 1996/1 April 1997; accepted 8 April 1997 